\title{
Continuous intention determinants in the use of food delivery application in Surabaya, Indonesia
}

\author{
S. Hariadi \& S. Rahayu \\ Universitas Indonesia, Indonesia
}

\begin{abstract}
This research aims to recognize and investigate the influence of information quality and UTAUTS on continuous intention in the use of FDA in Surabaya, Indonesia. 150 respondents, who have been users of FDAs for the last 6 months in Surabaya, filled out an online questionnaire as the research sample. This study customizes the SEM scheme with AMOS 22 and concludes that continuous intention is positively influenced only by hedonic motivation and not by other factors such as information quality, performance and effort expectancy, price value, facilitating conditions, or habit.
\end{abstract}

\section{INTRODUCTION}

\subsection{Background}

Information systems are a very large part of the use of technology in running a business. Many service companies customize their products with applications that are easily accessible via smartphones. This makes it easy for customers to make various transactions from anywhere and anytime.

One application that is widely used by smartphone users is food delivery applications (FDAs). People prefer buying ready-to-eat food through digital applications to cooking themselves or buying their own food (Valenta, 2019).

The results of the Nielsen Singapore survey show that $58 \%$ of Indonesians buy fast food via an online application from smartphones. People aged 18-45 years buy ready-to-eat food through an online food delivery application from smartphones as many as 2.6 times per week (Jayani, 2019). The main reasons consumers choose online applications are reduction of time and effort (39\% of respondents), attractive promotions or offers (33\% of respondents), practical payment options and cash discounts ( $21 \%$ of respondents), and a variety of food menu choices (17\% of respondents).

Meanwhile, Lee et al. (2019) employed the unified theory of acceptance and use of technology model to increase the quality of information in identifying the elements of continuous intentions of FDAs for 340 respondents in South Korea. Habit has the sturdiest impact on continuous intention, as shown by performance expectancy and social influence. Information quality does not directly influence intentions of continuing use through performance expectations.

This work emphasizes the importance of information quality, performance expectancy, habit, and social influence as driving factors for users' intention to keep using FDAs. The findings build on previous research in online business in the food service sector. This study was conducted by taking case studies of the FDA in Indonesia, namely GoFood and GrabFood.

\section{LITERATURE REVIEW}

\subsection{Information quality}

In the era of information technology, all the businesses in the world require accurate information. Information quality is the gradation to which evidence has pleased, form, and time characteristics, which give it value for certain end users (Rai et al. 2002; O'Brien, 2005). 
Information quality also pertains to the degree, soundness, and usefulness of information, which is the yield of an information system and the eminence of the output (Ranganathan \& Ganapathy, 2017; Lee et al. 2019). Good quality information creates pleasure when using and the intention to behave positively (Ahn et al. 2007). Consumers' positive perceptions about the quality of information are formed when evidence encounters opportunities during the pronouncementmaking procedure and sufficient information is available (Corbitt et al. 2003; Kim \& Park, 2013).

A literature review on technology receiving demonstrations that conviction in information is a feature influencing behavioral meaning (Yadav et al. 2016; Sharma et al. 2016). These arguments are the basis for formulating the following hypothesis.

H1: Information quality drive significantly impacts continuous intention.

$\mathrm{H} 2$ : The information quality of FDA will significantly impact expectancy.

H3: The information quality of FDA will significantly impact behavioral intention.

\subsection{Unified theory of acceptance and use of technology}

Many studies use TAM (Technology Acceptance Model) to explain technology acceptance. This model has a weakness, namely, it cannot properly explain the effect of various exogenous variables on the TAM variable. Venkatesh et al. (2003) refined the TAM model by proposing a comprehensive model, namely, the intention to practice and user behavior of the information system UTAUT. Performance expectations, business expectations, social influences, and facility conditions are direct determinants of behavioral intention and use.

Performance expectations also refer to the extent to which individuals believe that the use of the system will help in improving their occupation performance (Yadav et al. 2016). Business expectations denote the affluence of practice of the structure. Positive perceptions of ease of use will lead to a greater intention to use technology (Lawan \& Dahalin, 2011; San Martin \& Herrero, 2012). Social influence shows that the practice of systems or technology is influenced by peer views (Yeo et al. 2017). Facility conditions are demarcated as the level of individual confidence in the existence of prearranged practical sustenance for system use (Jati \& Laksito, 2012).

This study places these seven variables as factors that influence continuous intention for using a food delivery application. The hypotheses proposed are as follows:

H4: Expectation of FDA performance will significantly impact continuous intention.

H5: Attempted FDA expectations will significantly influence continuous intention.

H6: The social influence associated with FDA will significantly impact continuous intention.

H7: The facilitation conditions regarding FDA will significantly impact continuous intention.

H8: The hedonic motivation regarding application delivery will significantly impact continuous intention.

H9: The value of the delivery application price will significantly impact continuous intention.

H10: Customs with respect to delivery applications will significantly impact continuous intention.

\section{METHODS}

This research is a causal research that explains cause and effect. The data source is primary data obtained by distributing questionnaires to food application delivery users. The validity and reliability of the questionnaire were tested using a sample of 30 respondents. They were all users of food application delivery in Surabaya, Indonesia. The respondents are users of food application delivery in the last 6 months with a do-it-yourself process, both male and female, and at least 17 years old. The model measurement uses the confirmatory factor analysis. The structural model was analyzed using the AMOS program. 


\section{RESULTS}

This study used a sample of 150 respondents in accordance with predetermined characteristics. $64.7 \%$ of the respondents were women, and $35.3 \%$ were men. Respondents aged $17-24$ years comprised $91.3 \%$ of the sample, and those with senior high school education comprised $74 \%$, followed by bachelors degree $(25.3 \%) .82 \%$ of the respondents were students.

\subsection{Measurement model}

The results of confirmatory factor analysis show that each indicator has a standardized loadings value greater than 0.5 and the resulting AVE value also greater than 0.5 . The indicators that make up each research variable, namely, information quality, habit, effort expectancy, performance expectancy, price value, continuance intention, facilitating conditions, hedonic motivation, and social influence, have shown good measurements. The value of construct reliability in each variable is above 0.6 . This means that these indicators have good reliability. The criteria for the validity and reliability of the measurement model are good. This is also supported by the goodness-of-fit criteria for the measurement model.

\subsection{Structural model}

The structural model of the research is the effect of information quality, effort expectancy, social influence, price value, facilitating conditions, hedonic motivation, performance expectancy, and habit regarding the continuous intention of users of GoFood and GrabFood applications. The structural model was analyzed using the AMOS program (Figure 1).

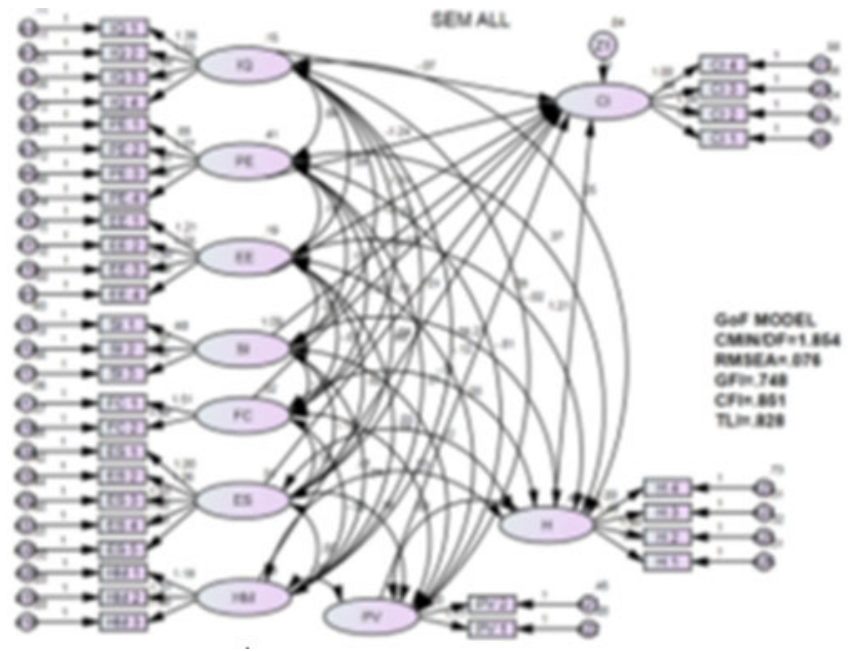

Figure 1. Structural model.

The structural model evaluation has some criteria. The goodness-of-fit value has met the established criteria. Only the TLI and CFI values of 0.828 and 0.851 are included in the Marginal Fit category. Thus, testing the research hypothesis can use the results of the structural model.

\subsection{Hypothesis testing and discussion}

Inter-variables have a significant effect if the significance value is $<0.05(\alpha=5 \%)$ or CR $>1.96$. This study shows that performance expectancy and effort expectancy have no positive effect on continuous intention of FDA users. FDA use is commonplace. Regardless of the conditions, the user will continue to use them because of the demands of convenience, practicality, and other things related to the user's lifestyle. 
Price value has no positive effect on continuous intention by FDA users. Users will continue to use the FDA for other reasons. The costs incurred are often not worth the effort if they have to leave the house to buy food.

Facilitating conditions and habits have no positive effect on continuance intention by FDA users. This is because the facilities made available by FDAs are commonplace and it has become a daily habit for users to use various applications, so they will continue to be used in the future.

Hedonic motivation has a positive effect on continuance intention of FDA users. This is because FDAs facilitate the desire to enjoy various trends in the culinary world easily.

Information quality has no positive effect on continuance intention of FDA users. This is because almost all application-based services provide complete services, so that no matter what information is available, the user will still use FDAs.

Social influence has no positive effect on the continuance intention of FDA users. FDAs have become a trend, so their use is not due to the social influence of the people around the users.

\section{CONCLUSION}

Continuous intention is positively influenced only by hedonic motivation and not other factors such as information quality, performance and effort expectancy, price value, facilitating conditions, or habit.

\section{REFERENCES}

Ahn, T.; Ryu, S.; \& Han, I. 2007. The impact of web quality and playfulness on user acceptance of online retailing. Information Management. 44: 263-275.

Corbitt, B.J.; Thanasankita, T.; \& Yi, H. 2003. Trust and e-commerce: A study of consumer perceptions. Electronic Commerce Research and Applications. 2: 203-215.

Jati, N.J. \& Laksito, H. 2012. Analysis of the factors that influence interest in the use of the e-ticket system: Empirical study of travel agents in Semarang city. Diponegoro Journal of Accounting. 1(1): 512-524.

Jayani, D. H. 2019. Ordering Food Online is More and More Popular. https://databoks.katadata.co.id/ datapublish/2019/09/19. Downloaded at 1 August 2020.

Kim, S. \& Park, H. 2013. Effects of various characteristics of social commerce (s-commerce) on consumers' trust and trust performance. International Journal of Information Management. 33: 318-332.

Lawan, A. \& Dahalin Z. M. 2011. Effectiveness of Telecentre using a Model of Unified Theory of Acceptance and Use of Technology (UTAUT): SEM Approach. CIS Journal. 2(9): 402-412.

Lee, S. W., Hye J. S. \& Hyeon M. J. 2019. Determinants of Continuous Intention on Food Delivery Apps: Extending UTAUT2 with Information Quality. Sustainability. II: 3141.

O’Brien, J. A. 2005. Introduction to Information Systems. Salemba Empat. Jakarta

Rai, A., Lang, S.S. \& Welker, R.B. 2002. Assessing the Validity of IS Success Models: An Empirical Test and Theoretical Analysis. Information System Research. 13(1): 29-34.

Ranganathan, C. \& Ganapathy, S. 2017. Key dimensions of business-to-consumer websites. Information Management. 39: 457-465.

San Martin, H. \& Herrero, A. 2012. Influence of the user's psychological factors on the online purchase intention in rural tourism, integrating innovativeness to the UTAUT framework. Tourism Management. 33: $341-350$.

Sharma, S.K.; Joshi, A.; \& Sharma, H. 2016. A multi-analytical approach to predict the Facebook usage in higher education. Computers in Human Behavior. 55: 340-353.

Valenta, E. 2019. The food ordering application changes the behavior of Indonesian consumers. https://beritagar.id/artikel/berita. Downloaded at 1 August 2020

Venkatesh, V.; Morris, M.G.; Davis, G.B.; \& Davis, F.D. 2003. User acceptance of information technology, toward a uni?ed view. MIS Quarterly. 27: 425-478.

Yadav, R.; Sharma, S.K.; \& Tarhini, A. 2016. A multi-analytical approach to understand and predict the mobile commerce adoption. Journal of Enterprise Information Management. 29: 222-237.

Yeo, Vincent; See, K.G.; \& Sajad, R.; 2017. Consumer experiences, attitude and behavioral intention toward online food delivery (OFD) services. Journal of Retailing and Consumer Services. 35:150-162. 